\title{
A Study to Evaluate the Musculoskeletal Disorder among Dentists in Sri Ganganagar City, Rajasthan
}

\section{Neha ${ }^{1}$, Aniyo R $^{2}$, Kaur G ${ }^{3}$, Kashyap N ${ }^{4 *}$, Arora S $^{5}$ and Ankita ${ }^{6}$}

Department of Pedodontics and Preventive Dentistry, Maharaja Ganga Singh Dental College and Research Centre, India

*Corresponding author: Kashyap N, Department of Pedodontics and Preventive Dentistry, Maharaja Ganga Singh Dental College and Research Centre, India, Tel: 7987020593; Email: nilkash9365@gmail.com

\section{Research Article \\ Volume 5 Issue 1}

Received Date: February 05, 2020

Published Date: March 20, 2020

DOI: $10.23880 /$ oajds- 16000245

\section{Abstract}

Background: Musculoskeletal disorders among dentists have been significant for many years. It affects the health and longevity of the working population. Therefore it is necessary to identify the occurrence of common musculoskeletal disorders among dentists. So that necessary prevention and precaution can be taken and thereby manage them.

Method: Questionnaire was distributed among all the dentist of Sriganganagar city which has four parts. Part1 consisted of demographic information of the dentist such as name, age, gender, height, weight and speciality. Part 2 was work related data about number of working days, working hours per day, number of patient per day, time taking for each patient, break time for each patient, feeling discomfort while taking patient, total working time per week and awareness of ergonomic chair. Part3 consisted of work related tools used like air driver/rotator, precision hand instrument and regular hand instrument. Part 4 was body parts affected by musculoskeletal disorder like neck, shoulder, elbows, wrist/hand, upper back, lower back, hip, knees, foots/ankle, eyes fatigue.

Result: Results showed that most of the dentists suffered from MSD's and the parts of body affected were varied according to the types of work and tools used.

Conclusion: The result suggested that the prevalence of musculoskeletal disorder among the dentist was high in this city. The common parts of the body affected were eyes, neck, shoulder, upper back and lower back.

Keywords: Musculoskeletal disorder; Precision; Ergonomics

\section{Introduction}

Health of the dentist is the most important factor for successful dental practice. Studies in 2000, by Contract et al, showed that one out of 10 dentists had poor general health and three out of ten dentists had poor physical state [1]. Disorders of the muscle ligaments, tendons, nerves, discs, cartilage and joints are described as musculoskeletal disorder.
They affect the productivity and longevity of occupation and health of the working population. Musculoskeletal disorder most commonly shows like pain, stiffeness, weakness, numbness and paraesthesia [2-7]. Repetitive awkward or stressful motions causes musculoskeletal disorder because of overstrained and awkward posture in back, neck and shoulder. Dentists and dental hygienists are seemed to be at the high risk for musculoskeletals disorders as compared 


\section{Open Access Journal of Dental Sciences}

to general population [8-10]. Hand neuropathy was also reported due to usage of high frequency vibration tools [11].

Nowadays ergonomics has been a popular term among most of the professions, especially increasing in dental profession. Ergonomics is derived from Greek words where ergo means work and names means natural laws. In a simple way ergonomics means working in a smarter way by modifying and designing equipments and tools used. So there is a necessicity for ergonomical design which can prevent repetitive strain injuries [12]. Although it is difficult to identify accurately the causes and risk factors for musculoskeletal disorder, some of the common risk factor can be posture, force, cold temperature, mechanical stress, extrinsic stress, repetitive vibration [13-17]. Work related pain is therefore common in dental profession which should be identified and managed. Hence it is very important to identify musculoskeletal problems so that it can be treated with multifaceted approaches like creating awareness through education and audio visual means.

\section{Material and Methods}

a) Study Design: Cross sectional study was done to find out the prevalence of musculoskeletal disorder in Sriganganagar city, Rajasthan.

b) Ethical Approval: Survey was approved by Ethical Committee of Maharaja Ganga Singh Dental College and Research Centre.

c) Study Location: Sriganganagar city, Rajasthan.

d) Sample Size: A total of 63 dentist participated in this study.

e) Inclusion: Both genders, both BDS and MDS, age 25 and above and working experience at least 2 years.

f) Exclusion: Dentist having known history of orthopaedics, cardiorespiratory and neurological illness.

\section{Methodology}

There were four parts in the questionnaire which was given to the participants. Part A of the questionnaire had questions about demographic information like name, age, gender, height, weight and speciality and also about awareness of posturedontics among the dentist. Part B consisted of work related information like working days per week, working hours per week, patient per day, time taking in each patient, time taking between each patient, feeling discomfort during working hours , bending towards patient, total working hour per week and awareness regarding ergonomic chair. Part $\mathrm{C}$ was regarding tools used in the clinic like driven/rotary instruments, using of precision hand instruments and regular hand instruments. Part D was about body parts affected by musculoskeletal disorder by using Standard Nordic Questionnaire like neck, shoulder, elbows, wrist/hand, upper back, lower back, hip, knees, foot/ ankle, and eye fatigue. The collected data were tabulated and subjected to statistical analysis using SPSS software version 20.0, (SPSS Inc., Chicago Ill., USA) and levels of statistical significance were set at $\mathrm{P}<0.05$.

\section{Results}

A total of 63 questionnaires were given to the dentist of Sriganganagar city, including BDS and MDS. All the 63 questionnaires were used for the data analysis (Table 1). The result suggested that most of the dentist suffered from MSD's but the body parts affected were based on different types of work and the various equipments or tools used during working. All the dentist had worked at least for 2 years (Graphs 1-4).

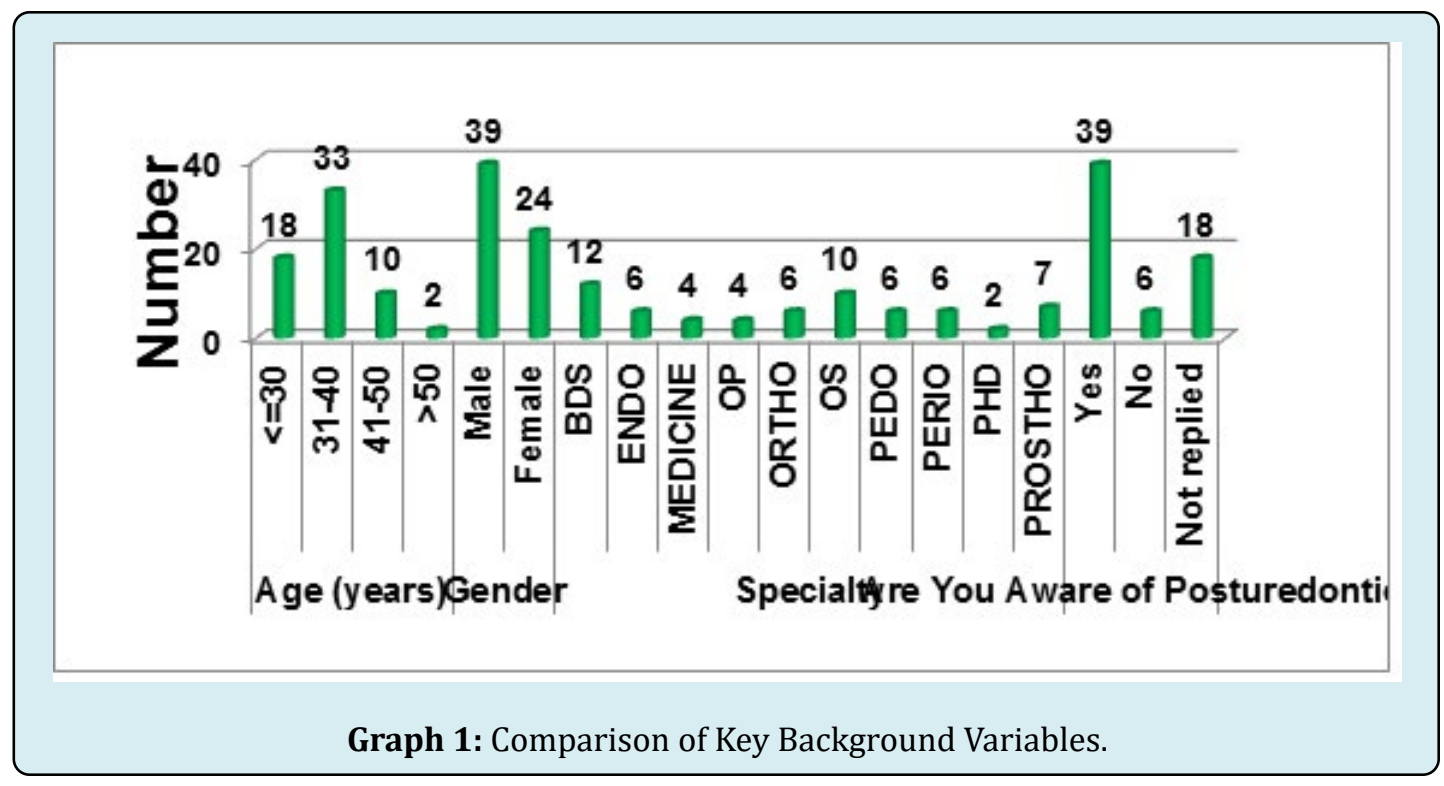




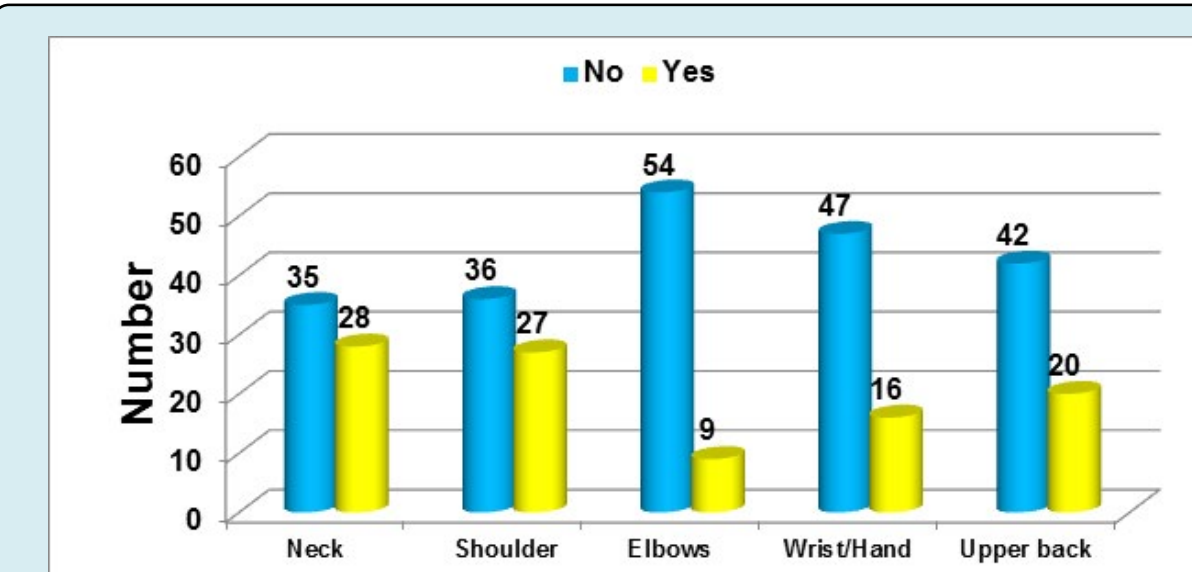

Graph 2: Body Parts Affected By Musculoskeletal Disorder.
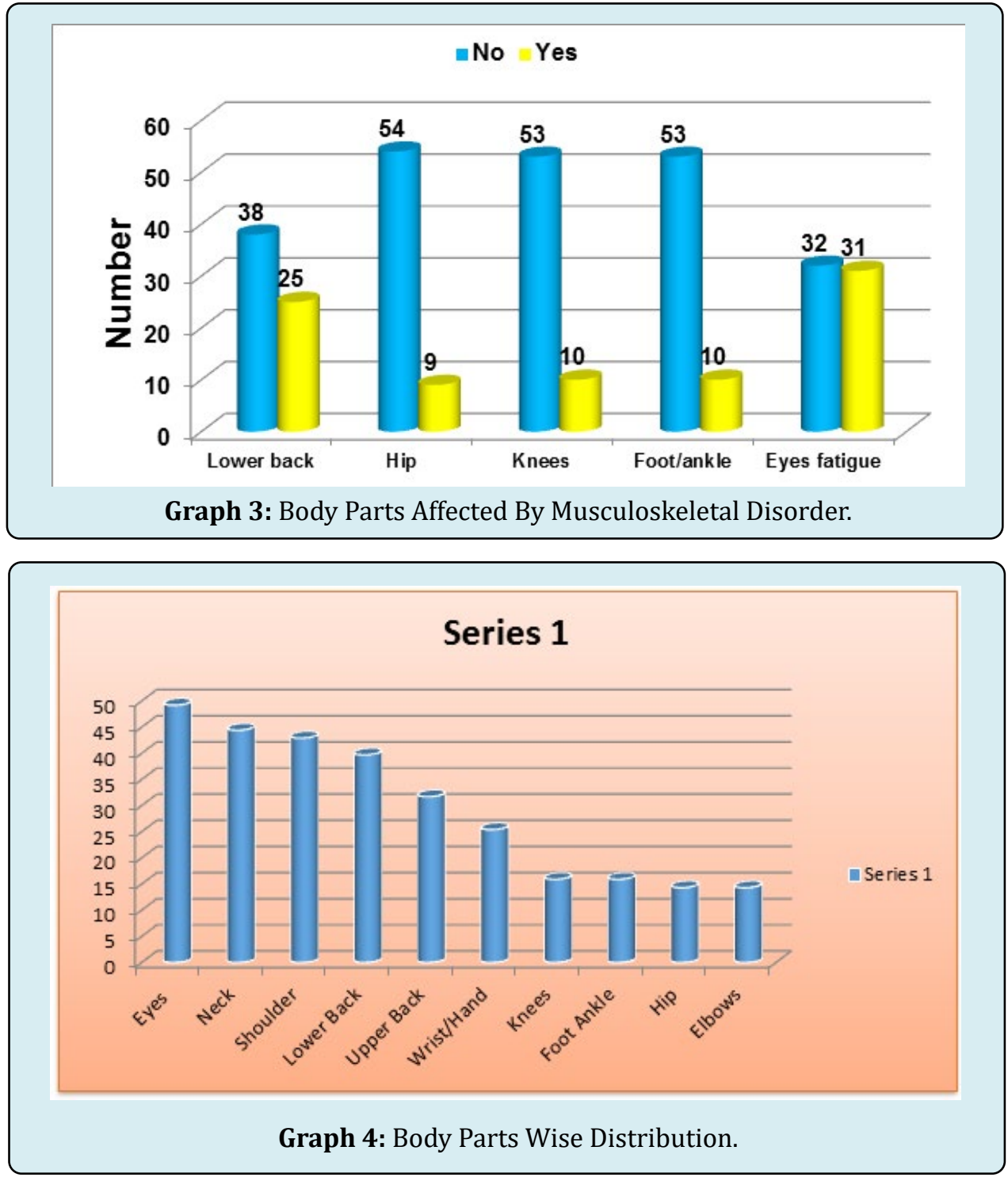


\section{Open Access Journal of Dental Sciences}

\begin{tabular}{|c|c|c|}
\hline Body Part & No \% & Yes \% \\
\hline Neck & $35(55.6 \%)$ & $28(44.4 \%)$ \\
\hline Shoulder & $36(57.1 \%)$ & $27(42.2 \%)$ \\
\hline Elbows & $54(85.7 \%)$ & $9(14.3 \%)$ \\
\hline Wrist/Hand & $47(74.6 \%)$ & $16(25.4 \%)$ \\
\hline Upper Back & $42(66.7 \%)$ & $20(31.7 \%)$ \\
\hline Lower Back & $38(60.3 \%)$ & $25(39.7 \%)$ \\
\hline Hip & $54(85.7 \%)$ & $9(14.3 \%)$ \\
\hline Knees & $53(84.1 \%)$ & $10(15.9 \%)$ \\
\hline Foot/Ankle & $53(84.1 \%)$ & $10(15.9 \%)$ \\
\hline Eye Fatigue & $32(50.8 \%)$ & $31(49.2 \%)$ \\
\hline
\end{tabular}

Table 1: Frequency Table.

\section{Discussion}

In this study there were 39 (61.9\%) of males and 24 (38.1\%) females. Majority of the participants belonged to 3140 years of age. Maximum number of dentist was BDS (19\%) and oral surgeons (15.9\%). There are numerous specialities in dentistry which have different work related disorders which needs treatment programmes. It was also reported that $61.9 \%$ of the dentist were aware of posturedontics and $9.5 \%$ were not aware and $28.6 \%$ did not answer. Oral surgeons, most of them spend their time in surgeries in a standing position for a long time. So, the most affected area was lower back and also there was a lot of eye strain. So eye fatigue was also very high. There was also involvement of wrist due to precision and fine manipulative hand movements. Oral pathologist usually suffered from neck and upper back fatigue due to constant use of microscopes, for endodontists affected areas were thumb and wrist which was very common because they managed root canal treatment with precision equipments for a very long period of time. For periodontists also precision equipments were the most important equipments to perform the flap surgeries and to take care of gums. So, hand and wrist were mostly affected.

Literature says that operating posture is the most important to prevent MSD. It also says that the operator posture should be in such a way that all the muscle should be in relaxed well balanced and in neutral position which can prevent musculoskeletal disorders [18]. Pedodontist mostly suffered from upper back because they used adult dental chair for treating paediatric patients according to which they tend to adapt the postures which can hamper the muscles and skeletal system. Usually prosthodontists seem to suffer from neck pain and cervical spine problems. While orthodontists are mainly involved with the esthetics which deals with wire bending and bonding the brackets to teeth. This can result into wrist and hand musculoskeletal disorders.

The present study reveals that there is a high prevalence
(78\%) of MSD among dentists in the city. This prevalence is same as Andhra Pradesh, Nellore (78\%), though higher than that reported by practitioners in, Iran (73\%), Mumbai (77\%), Jaipur (73.3\%), Surat, Gujarat (63.6\%), Navi Mumbai (57.5\%) and Kakaji New Delhi (58.99\%) but lower than the reports from Andhra Pradesh City (93\%) [19], South Africa (99.1\%), Australia (87.2\%) and Turkey (94\%) [20]. Assessment of other studies also reveals that the prevalence of MSD among dental practitioners in Navi Mumbai, Jaipur and Rasht, Iran have shown higher prevalence of MSD among female practitioners. But the current study reveals that there is no difference in prevalence of MSD between male and female practitioner. This could be due to small size $(\mathrm{N}=63)$ and most of the dentists were male practitioners. Whereas in Andhra Pradesh male and female prevalence was equal and male prevalence was found to be higher in Mumbai.

In the present study the commonly affected areas were eyes (49.2\%), neck (44.4\%), shoulders (42.9\%) and lower back (39.7\%). Other study found that neck was the most commonly affected part followed by shoulder. Where as in Mumbai and Bhimavaram, Andhra Pradesh [19] lower back was found to be the most affected area. Studies also found that dental practitioners in Lithuania and Poland had increased MSD with an increase in their age. But in the present study middle aged dentists were commonly affected. This could be due to the fact that most of the practitioners were between 31 to 40 years of age and also our study comprised of only 63 dental practitioners which could be the reason for this. In contrast other studies revealed that dental practitioners of Saudi Arabia and New South Wales [19] showed that MSD decreased with age. It could be due to taking up less number of patients as a result of age or with the years of practice and using better ergonomically oriented chair or by doing exercise, medications for MSD.

This study found that different body parts were affected due to their different kinds of work and also because of their different kind of speciality in dentistry. There are various reasons which can also predispose them to suffer like different types of work, different kind of tools used as well as the posture they used while working on patients. There should be thorough study and research to understand the physiological mechanism of these problems which is also important from physiotherapist point of view. It is not only treating the physical manifestation of MSD but also about altering the workplace. It should also be noted that different specialities has different kind of works, so keeping this in mind, ergonomics can be prescribed to prevent the reoccurrence of MSD in future.

\section{Conclusion}

So it can be concluded that the frequency of 
musculoskeletal disorders in Sriganganagar, city is high. Different body parts were affected which is not common with each other. The most commonly affected body parts were eyes, neck, shoulder, lower back and upper back.

\section{References}

1. Gorter RC, Eijkman MA, Hoogstraten J (2000) Burnout and Health among Deutch Dentists. Eur J Oral Sci 108(4): 261-267.

2. Craig HB, Banfield G, Knight J (2003) Prevalence of back and neck pain amongst ENT consultants: national survey. J Laryngol Otol 117(12): 979-982.

3. Hagberg M, Wegman DH (1987) Prevalence rates and odds ratios of shoulder-neck diseases in different occupational groups. Br J Ind Med 44(9): 602-610.

4. Holmstrom EB, Lindell J, Moritz U (1992) Low back and neck/shoulder pain in construction workers: occupational workload and psychosocial risk factors. Part 1: Relationship to low back pain. Spine 17(6): 663671.

5. Kvarnstrom S (1983) Occurrence of musculoskeletal, disorders in a manufacturing industry with special attention to occupational shoulder disorders. Scand J Rehabil Med S8: 1-114.

6. Vasseljen O, Westgaard RH (1995) A case-control study of trapezius muscle activity in office and manual workers with shoulder and neck pain and symptom-free controls. Int Arch Occup Environ Health 67(1): 11-18.

7. Yeung SS, Genaidy A, Deddens J, Alhemood A, Leung PC (2002) Prevalence of musculoskeletal symptoms in single and multiple body regions and effects of perceived risk of injury among manual handling workers. Spine 27(19): 2166-2172.

8. Akesson I, Johnsson B, Rylander L, Moritz U, Skerfving S (1999) Musculoskeletal disorders among female dental personnel-clinical examination and a 5-year followup study of symptoms. Int Arch Occup Environ Health 72(6): 395-403.

9. Rundcrantz BL, Johnsson B, Moritz U (1991) Pain and discomfort in the musculoskeletal system among dentists. A prospective study. Swed Dent J 15(5): 219228.

10. Szymanska J (2002) Disordes of the musculoskeletal system among dentists from the aspect of ergonomics and prophylaxis. Ann Agric Environ Med 9(2): 169-173.

11. Akesson I, Lundborg G, Horstmann V, Skerfving S (1995) Neuropathy in female dental personnel exposed to high frequency vibrations. Occup Environ Med 52(2): 116123.

12. Gupta S (2011) Ergonomics applications to the dental practice. Indian J Dent Res 22(6): 816-822.

13. Armstrong TJ, Lifshitz Y (1987) Evaluation and Design of jobs for control of Cumulative Trauma Disorders. Ergonomic Interventions to prevent musculoskeletal Injuries in Industry. Chelsea Lewis Publishers Inc.

14. Gerwatowski LJ, Mcfall DB, Stach DJ (1992) Carpel Tunnel Syndrome Risk Factors and Preventive Strategies for the dental hygienist. J Dental Hyg 66(2): 89-94.

15. (1998) Centre for Ergonomics. Introduction to Upper Limb Musculoskeletal Disorder. The University of Michigan College of Engineering, Ann Arbor, Online Training, Inc.

16. Carayon P, Smith MJ, Haims MC (1999)Work Organisation, Job Stress, and Work related Musculoskeletal Disorders. Human Factor 41(4): 644-663.

17. ANSI (1993) Control of Cumulative Trauma Disorders. ANSI 2-365 Illinois.

18. Alexopoulos EC, Stathi IC, Charizani F (2004) Prevalence of musculoskeletal disorders in dentists. BMC Musculoskelet Disord 5: 16.

19. Muralidharan D, Shanthi M, Fareed N (2013) Musculoskeletal Disorders among Dental Practitioners: Does It Affect Practice?. Epidemiology Research International, pp: 1-6.

20. Polat Z, Baskan S, Altan S, Tacir I (2007) Musculoskeletal symptoms of dentists from South-East Turkey. Biotechnology and Biotechnological Equipment 21(1): 86-90. 